\title{
Advertisement Click Fraud Detection
}

\section{Dhanvanth Kesavan}

Department of Computer Science \& Engineering, Vel Tech Rangarajan Dr. Sagunthala R\&D Institute of Science and Technology, Avadi, Chennai, Tamil Nadu, India

\section{ABSTRACT}

\section{Article Info}

Volume 7, Issue 3

Page Number: 364-369

\section{Publication Issue :}

May-June-2021

\section{Article History}

Accepted : 20 May 2021

Published : 29 May 2021
Mobile ads are tormented with deceitful clicks that may be an important test for the advertising network. Albeit documented promotion systems utilize various methods to acknowledge click fraud, they don't shield the client from conceivable intrigue among distributors and advertisement systems. What's additional, promotion systems can't screen the client's action for click fraud location once they're entertained to the advertising web content following clicking the ad, i.e., in a web site there will be focuses or some specific spots after we click on the actual spot it'll be entertained to the advertising web site. We propose another publically support-based mostly framework referred to as Click Fraud Crowdsourcing (CFC) that works in conjunction with the two promoters and advertisement organizes therefore as to defend the two gatherings from any conceivable click dishonorable acts. The framework profits by each a worldwide view, wherever it accumulates various promotion demands examining to various advertising organize distributer publicist blends, and a nearby read, wherever it will follow the clients' commitment in every advertising website.

Keywords : Fraudulent clicks, click fraud, advertising website, crowd-sourcebased system, ad network, users.

\section{INTRODUCTION}

\subsection{Introduction}

Click fraud is a type of fraud that happens on the Internet in pay-per-click (PPC) web-based advertising. In this sort of advertising, the proprietors of websites that post the advertisements are paid a measure of cash controlled by what number of guests to the sites click on the advertisements. Fraud happens when a person, computerized content, or PC program emulates an authentic client of a web program, clicking on such a promotion without having a genuine enthusiasm for the objective of the advertisement's link. Click fraud is the subject of some discussion and expanding prosecution because of the advertising systems being a key recipient of the fraud. Pay-per-click advertising. PPC advertising is a course of action where webmasters (operators of websites), going about as distributors, show clickable connections from sponsors in return for a charge per click. As this industry advanced, various

Copyright: () the author(s), publisher and licensee Technoscience Academy. This is an open-access article distributed under the terms of the Creative Commons Attribution Non-Commercial License, which permits unrestricted non-commercial use, 
advertising systems were created, which went about as go-betweens between these two gatherings (distributors and publicists). Each time an (accepted to be) legitimate Web client clicks on promotion, the publicist pays the advertising system, which thusly pays the distributer a portion of this cash. This income-sharing framework is viewed as a motivating force for click fraud. The biggest of the advertising systems, Google's AdWords/AdSense and Yahoo! Search Marketing act in a double job, since they are likewise barristers themselves (on their web indexes). As per pundits, this unpredictable relationship may make a contention of interest. This is on the grounds that these organizations lose cash to undetected click fraud when paying out to the distributor yet get more cash-flow when gathering expenses from the advertiser. Because of the spread between what they gather and pay-out, free click fraud would make transient benefits for these organizations.

\subsection{Aim}

The point of our undertaking is to identify the fraudulent advertising website and to make an answer for the issue by doing data analysis. Click fraud is a type of Deception that happens on the Internet in pay-per-click (PPC) web-based advertising. In this sort of advertising, the proproprietors of websites that post the ads are paid a measure of cash controlled by what number of guests to the sites click on the ads. so there will be some particular focuses or places in a website when somebody clicks that place, they will be coordinated to the fraudulent advertising webpage so by making data analysis we can have the option to follow the particular focus where the fraud happens in the website.

\subsection{Scope}

Our aim of the report was to safeguard the protection of the fraud-detection framework so as to keep up its viability. This provoked a few specialists to lead open research on how the mediators can battle click fraud. Since such research is apparently not spoiled by showcase powers, there is trust that this exploration can be received to survey how thorough a broker is in distinguishing click fraud in future law cases. The dread that this examination can uncover the interior fraud-detection arrangement of go-between still applies.

\subsection{Methodology}

Since there are such huge numbers of various sorts of promotion fraud, detecting it is tricky. Luckily there are various organizations out there that spend significant time in distinguishing advertisement fraud, with most contribution a boycott arrangement that keeps fraudulent movement from influencing future web-based advertising efforts. Generally, these organizations use calculations to recognize fraudulent conduct, for example, unusually high CTRs and poor or no crusade performance (for example five hundred fifty clicks however no transformations). From that point, these advertisement fraud detection organizations can boycott certain URLs and IP addresses.

\section{LITERATURE REVIEW}

\subsection{Return of Investment}

Niche Market Strategy - With Pay-Per-Click advertisement campaigns, you can focus on your ad to specific niche markets, days of the week, times and target specific urban areas or specific nations to pick up traffic from your optimal objective audience. Seasonal Marketing Strategies. Apparently, the best benefit of Pay-Per-Click Marketing is that you can pick when to show your crusades to the season. During more slow seasons when you may not be accepting a lot of traffic, you can kill your ad crusade or ' interrupt' it. You can likewise expand your payper-click advertising during a bustling occasion 
season. Double Branding Exposure, Larger brands that have accomplished a spot on the primary page of Google directly will likewise make Pay-Per-Click advertisement campaigns show up twice on a quest for absolute presentation and page domination Longtail catchphrases. People are aiming to be savvier with concerns to figuring out what they need to discover through the online web search tools. Furthermore, through discourse acknowledgment increasingly more long-tail watchwords are being utilized. For example, instead of composing an inquiry, for example, "Rice Barn," clients may now type or spare inquiries as an examination," how much will Rice barn cost go up one year from now?'That would be a long fabrication search or a long tail catchphrase. On the off chance that you remember that, at that point, PPC can be truly beneficial profit for your investment. mensurable ROI - It is anything but challenging to quantify outcomes with Pay-PerClick Marketing. There are numerous measurements out

there holding back to be recognized such to be those on Pay-Per-Click The investigation that you can use to quantify the viability of your battle regarding the level of profitability. You will moreover have the possibility to discover the number of watchers who saw the ad, the number of clicks, and if watchers responded to the ad as you anticipate that they should. With some PPC suppliers, you can even trace calls and attune them

to check whether they are the correct kind of interrogations.

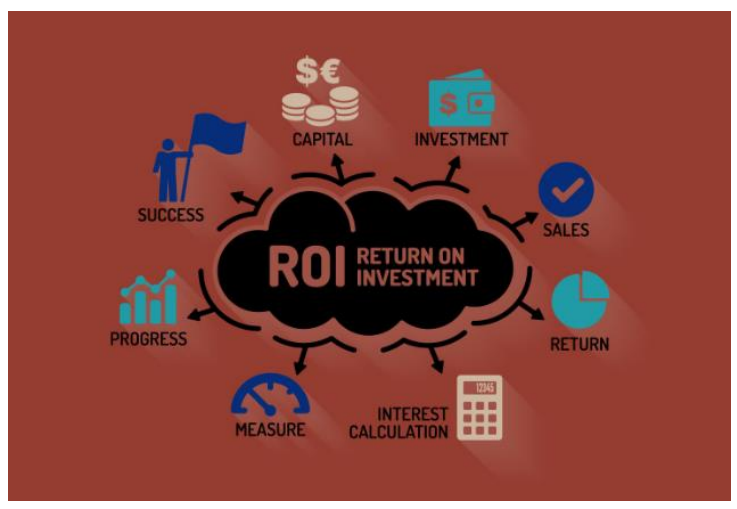

\section{Fig 2.1 ROI}

\section{DESCRIPTION}

\subsection{Existing System}

Click fraud may be a dishonest strategy that's predominant. It happens for the most part on online advertisements with an aim on Pay-per-Click financial gain age. Click fraud is that the subject of some discussion and expanding prosecution attributable to the advertising systems being a key recipient of the fraud. Pay-per-click advertising. Such advertising is that the purpose at that the distributor or man of affairs of the web site posts advertisements or delineated ad battles and square measure paid certain whole of money supported the number of guests visiting the web- page click on the association's advertisement. In such circumstances fraud happens once a framework, a content, or someone performs fraud or foolish clicks simply to accomplish sure objectives that thus achieve the age of financial gain. this is often finished by purposefully clicking on the targeted advertising with much zero enthusiasm for the substance of the connection.

\section{* Advantages:}

Quantifiable Return on Investment (ROI), Attain the Correct folks at the Correct Time, Targeted Marketing, Quick Impact, whole Exposure, Limit the Spend.

* Disadvantages:

Timely investment, knowledge needed, prices will be instantly added up, Clicks and visits don't perpetually cause sales.

\subsection{Feasibility Study}

The apprehension of factory-made Ad-Reports may be a distressing issue since clients need to stay unknown, and secrecy for stalls confirmation 
through ancient techniques, for example, computerized marks. To determine this issue, we tend to propose Associate in Nursing discretionary maneuverings for establishing accurate reports while easily permitting clients to keep up their obscurity. Clients are often named honest or consumptive obsessed with the approach whereupon they create Ad-Reports.

\section{METHODOLOGIES}

Since there conventional degree such an oversized assortment of varied styles of advertisement fraud, distinctive it's dubious. luckily there square measure varied institutions out there that have sensible expertise in identifying advertisement fraud, with most contributions a boycott arrangement that keeps dishonest action from influencing future web advertising efforts. Generally, these systems use computations to tell apart deceitful conduct, for the situation, unusual high CTRs, and poor or no cruComte Donatien Alphonse Francois de Sade performance (for instance seven thousand clicks but no alterations). From that time, these ad-fraud detection organizations will boycott sure URLs and information processing addresses. Some of the approaches for fraud detection are:

\footnotetext{
$>$ Sampling

$>$ Ad-Hoc

$>$ Repetitive or Continuous analysis

$>$ Benford's Law
}

\subsection{SAMPLING}

Sampling is obligatory for specific procedures of fraud detection. Sampling is progressively viable wherever there a good deal of information world enclosed. nevertheless, at a similar time, it's its disadvantage. Sampling can presumably be unable to utterly management the fraud detection because it contemplates simply scarcely any world. Fraudulent exchanges don't happen haphazardly during this manner Associate in Nursing association have to be compelled to take a look at all the exchanges to viably distinguish fraud.

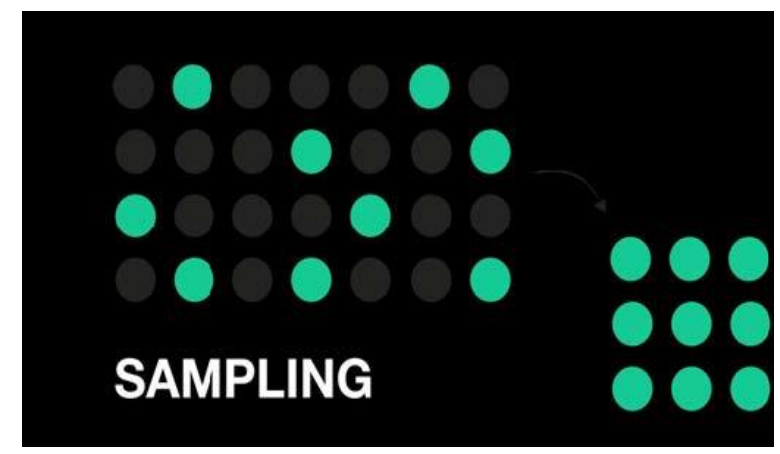

Fig 4.1.1 Sampling

\subsection{AD-HOC}

Ad-Hoc is simply discovering deceit by strategies for speculation. It permits you to analyze. you'll be able to check the exchanges and see whether or not there are any open doors for deception to happen. You can have a theory to check and see whether or not there's any deceitful movement happening and later you'll be able to examine the equivalent.

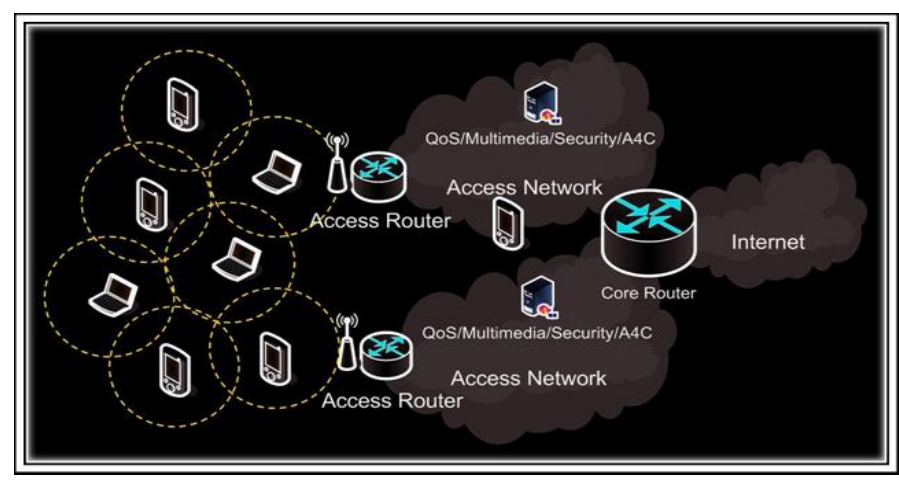

Fig 4.2.2 Ad-HOC

\subsection{REPETITIVE OR CONTINUOUS ANALYSIS}

Repetitive or Competitive Analysis implies creating and putting in place contents to run against the huge volume of information to differentiate the frauds as they happen over some indefinable time frame. Run the content daily to expertise all the exchanges and obtain periodic warnings with relevance to the frauds. This strategy will facilitate in rising the final 
productivity and consistency of your fraud detection forms.

\subsection{BENFORD'S LAW}

Benford'slaw will frequently be used as a marker of dishonest knowledge. Benford's distribution is nonuniform with smaller digits virtually certain than the larger digits. exploitation Benford'slaw you'll check sure points and numbers and acknowledge those that show up each currently and once more than they're alleged to and afterward they're the suspect

\section{RESULTS AND DISCUSSIONS}

Benford'slaw shall often be used as a marker of dishonest data. Benford's distribution is non-uniform with smaller digits virtually certain than the larger digits. exploitation Benford'slaw you'll check certain points and numbers and settle for those which show up each presently and yet again then they're speculated to and later on we tend to planned another crowd source-based system that collaborates with the two advertisers and ad networks thus on shield the two parties from click deceitful acts. this methodology manages ad getting and ad clicks and monitors the movement of happy users on the ad web site. it's able to follow the user's term in each advertising web site and at an equivalent chance to assemble numerous ad requests data corresponding to various advertisement organize publisher-advertiser combos. The data accumulated firmly in our planned model are usually used as an improvement to the CPA model. Our results showed that our planned policy is adjusted to bring down the warning rate (FPR=0 with $\mathrm{CFCAST}=30$ ) once characteristic click fraud as against planned solutions in writing (FPR=1) whereas having a high unambiguous definite rate (TPR=0.93 with CFCAST=30). Our structure suffers from three principle limitations: it desires an extra step conducted by the advertisement system to combine its library with the phone CFC library, it grants security worry since the scientific discipline related to the user application and timestamp is distributed to the CFC server, and it desires the advertisers and ad networks to trust the CFC Party.

\section{CONCLUSION AND FUTURE ENHANCEMENTS}

\subsection{Future Enhancements}

In any case, our structure suffers from three primary limitations: it wishes an additional step to be performed by the ad system to consolidate its library with the phone CFC library, it presents a privacy worry since the information processing related to the user application and timestamp is distributed to the CFC server, and it needs the advertisers and ad networks to trust the CFC party. In future work, we have a tendency to tend to are RMV execute a crowd source-based calculation that detects whether or not or not associate publicist is abused bytes competitors, and whether or not or not the user places in an exceedingly promulgated application merely just in case she is redirected among the wake of clicking the ad, to an application transfer page instead of an advertising site

\subsection{Conclusion}

Conclusion Ad fraud could also be a silent killer for retail leaders who chow up advertising budgets, Advertising strategy is disrupted through processed attacks together with basic ad fraud, click fraud, and audit fraud. Even below the tiniest quantity favorable conditions, these fraud schemes mean retailers lose out on necessary visibility to every consumer. for every animate being that intercepts a processed ad see, that's one less real person who may have seen the ad. use caution regarding choosing ROI alternatives supported clicks and impressions which is able to be merely faked by bots to expand the numbers. target real metrics that move the needle: a sign-ups, sales, and completely different conversions that are necessary to rock bottom line. Monitor activity data 
and pay regard for any value uncommon, like spikes within the range of clicks and click on-through rates, and what seems to be driving them. supported this analysis, blacklist low-quality sites that are driving traffic whereas not corresponding conversions. an interest in audit fraud might be worth millions in penalties.

\section{REFERENCES}

[1]. Asdemir, Kursad; Yurtseven, O” zden; Yahya, Mon (2008)."An Economic Model of Click Fraud in Publisher Networks".

[2]. Schonfeld, Erick (October 8, 2009; The Evolution Of Click Fraud: Massive Chinese Operation DormRing1 Uncovered". TechCrunch. [3] Badhe, Anup (April 2016). "Click Fraud Detection in mobile ads served in programmatic exchanges" (PDF). International Journal of Scientific Technology Research. 05: 1.

[3]. Majumdar, Saugat; Kulkarni, Dhananjay; Ravishankar, Chinya (2007). "Addressing Click Fraud in Content Delivery Systems" (PDF). Infocom. IEEE.

[4]. Google click fraud, http://www.law.com/jsp/article.jsp?id=11532135 25657.

[5]. N. Kshetri. The economics of click fraud. IEEE Security \& Privacy,8(3):45-53, May 2010

\section{Cite this article as :}

Dhanvanth Kesavan, "Advertisement Click Fraud Detection", International Journal of Scientific Research in Computer Science, Engineering and Information Technology (IJSRCSEIT), ISSN : 24563307, Volume 7 Issue 3, pp. 364-369, May-June 2021. Available at doi : https://doi.org/10.32628/CSEIT217375 Journal URL : https://ijsrcseit.com/CSEIT217375 